Running Head: CFA of the SIS-C

\title{
Confirmatory Factor Analysis of the Supports Intensity Scale for Children
}

Miguel A. Verdugo (verdugo@usal.es); Institute on Community Integration (INICO), University of Salamanca, Avda. de la Merced, 109-131, 37005 Salamanca, Spain

Verónica M. Guillén (veronicaguillen@usal.es); Institute on Community Integration (INICO), University of Salamanca, Avda. de la Merced, 109-131, 37005 Salamanca, Spain

Benito Arias (ㅁaias@psi.uva.es); Department of Psychology, University o Valladolid, Paseo de Belen 1, Campus Miguel Delibes, 47011 Valladolid, Spain

Eva Vicente (evavs@ usal.es); Institute on Community Integration (INICO), University of Salamanca, Avda. de la Merced, 109-131, 37005 Salamanca, Spain

Marta Badia (badia@usal.es); Institute on Community Integration (INICO), University of Salamanca, Avda. de la Merced, 109-131, 37005 Salamanca, Spain

Corresponding author:

Verónica M. Guillén (veronicaguillen@usal.es) +34923294500 Ext. 3327 INICO-University of Salamanca. Av. de la Merced, 109-131, 37005, Salamanca

\section{Acknowledgments}

Work on this research was funded by the Spanish Ministry of the Economy and Competitiveness (R\&D Projects, PSI2012-36278), and the Autonomous Community of Castile and Leon (R\&D Projects, SA120U13). 


\begin{abstract}
Support needs assessment instruments and recent research related to this construct have been more focused on adults with intellectual disability than on children. However, the design and implementation of Individualized Support Plans (ISP) must start at an early age. Currently, a project for the translation, adaptation and validation of the Supports Intensity Scale for Children (SIS-C) is being conducted in Spain. In this study, the internal structure of the scale was analyzed to shed light on the nature of this construct when evaluated in childhood. A total of 814 children with intellectual disability between 5 and 16 years of age participated in the study. Their support need level was assessed by the SIS-C, and a Confirmatory Factor Analysis (CFA), including different hypotheses, was carried out to identify the optimal factorial structure of this scale. The CFA results indicated that a unidimensional model is not sufficient to explain our data structure. On the other hand, goodness-of-fit indices showed that both correlated first-order factors and higher-order factor models of the construct could explain the data obtained from the scale. Specifically, a better fit of our data with the correlated first-order factors model was found. These findings are similar to those identified in previous analyses performed with adults. Implications and directions for further research are discussed.
\end{abstract}

Keywords: intellectual disability, support needs, assessment, confirmatory factor analysis, Support Intensity Scale for Children.

\title{
1. Introduction
}

Diagnosis and classification of intellectual disability has been a topic of major interest to those attempting to understand this phenomenon in relation to the complexity of intervention in this field. However, since the adoption of the new socio-ecological approach to the study of intellectual disability, evaluation in this field is currently defined as a systematic collection of 
information to fulfill three functions (Schalock et al., 2010; Schalock \& Luckasson, 2013a, 2013b): (1) diagnosis; (2) classification; and (3) support profile/ planning, which emphasizes the importance of intervention systems based on support needs assessment.

Support needs are defined as "a psychological construct that refers to the pattern and intensity of supports necessary for a person to participate in activities linked with normative human functioning" (Thompson et al., 2009, p.135). Most psychological constructs are not directly observable and latent variable methodologies must be used to capture them. Specifically, Verdugo (1994) claimed that the most recommended tools to infer such constructs in people with intellectual disabilities and help professionals develop clinician judgments were standardized measurement scales.

However, developing proper instruments requires a long and rigorous process yet assessments have not kept pace with the rapid developments in theoretical understanding of intellectual disability. Specifically, the shortage of support needs assessment instruments is an obstacle to the implementation of Individualized Support Plans (ISP) and, ultimately, to organizational change (Schalock \& Verdugo, 2012).

One of the methods used to solve this problem was to estimate support needs once the scores had been obtained using adaptive behavior scales. The Inventory for Client and Agency Planning (ICAP) (Bruininks, Hill, Weatherman, \& Woodcock, 1986) was one of the scales most commonly used for this purpose. However, many differences between the two constructs and the way in which they should be evaluated have been showed (Thompson, McGrew, \& Bruininks, 2002; Thompson et al., 2009). In assessing adaptive behavior, respondents report on whether a person performs specific skills; however, assessing supporting needs requires clarification of the support a person needs in order to perform life activities (Shogren et al., 2014). Furthermore, 
other related studies (Arnold, Riches, \& Stancliffe, 2014b; Wehmeyer et al., 2009) have found that the support needs construct better predict allocation and funding needs.

For that reason, creating an assessment scale to provide indices and profiles for specific support needs has become one of the greatest demands of planning teams and the scientific community (Thompson et al., 2002). Specific support needs assessment instruments have recently been developed for people with intellectual and developmental disabilities: (a) Service Need Assesment Profile, SNAP (Gould, 1998; Guscia, Harries, Kirby, Nettelbeck, \& Taplin, 2005); (b) North Carolina Service Need Assessment Profile, NC-SNAP (Hennike, 2002; Hennike, Myers, Realon, \& Thompson, 2002; Hennike, Myers, Realon, \& Thompson, 2006); (c) Instrument for the Classification and Assessment of the Support Needs, I-CAN (Arnold, Riches, \& Stancliffe, 2014a; Llewellyn, Parmenter, Chan, Riches, \& Hindmarsh, 2005; Riches, Parmenter, Llewellyn, Hindmarsh, \& Chan, 2009a, 2009b); and (d) Supports Intensity Scale for Adults, SIS or SIS-A (Thompson et al., 2004; Thompson, Bryant et al., in press).

However, the lack of valid instruments and research regarding support needs in people with intellectual disability is still evident. The SIS is the only scale with considerable international evidence of reliability and validity (e.g., Schalock et al., 2008; Thompson, Tassé, \& McLaughlin, 2008) that has been translated in Spanish (Verdugo, Arias, Ibáñez, \& Gómez, 2006; Verdugo, Arias, Ibáñez, \& Schalock, 2010; Verdugo Ibáñez, \& Arias, 2007).

This scale measures the type, frequency, and daily time of the support that the person needs in a total of 49 daily activities, which are grouped into six life-activity areas (Home Life, Community Living, Lifelong Learning, Employment, Health and Safety and Social). Similarly, the SIS gathers supplementary information related to protection/advocacy support needs, and exceptional medical and behavioral conditions. 
Although the SIS has been specifically developed to assess support needs in adults (16-64 years old) with intellectual disability, its potential for a modified version to be used for assessing support needs in adults with support needs relating to disabilities other than intellectual disability has also been explored (Bossaert et al., 2009; Cruz, Jenaro, Pérez, \& Robaina, 2010; Jenaro, Cruz, Pérez, Robaina, \& Vega, 2011; Smit, Sabbe, \& Prinzie, 2011). Moreover, this instrument has demonstrated its usefulness as part of the development of ISP (van Loon, 2006, 2009), its efficacy to predict resource allocation (Chou, Lee, Chand, \& Yu, 2013; Fortune et al., 2008; Giné et al., 2014; Wehmeyer et al., 2009) and its relationships with clinical scores (Weiss, Lunsky, Tassé, \& Durbin, 2009).

Despite the multiple advantages and the widespread use of this scale, it cannot be administered to children with intellectual disability, as the development of this scale was based only on typical adult activities. Therefore, taking into account the positive impact of this tool, as well as the right of children with intellectual and developmental disabilities to receive early interventions that guarantee their participation in the community (Colver, 2005), the American Association on Intellectual and Developmental Disabilities (AAIDD) has built up an international project focused on developing a Support Intensity Scale for Children (SIS-C) (Thompson, Wehmeyer et al., in press).

After the creation and study of an original pool of items (Thompson et al., 2014) to adapt this scale to the typical activities in childhood, a rigorous procedure was carried out to adapt and validate these items in the Spanish context (Guillén, Verdugo, Arias, \& Vicente, 2015; Verdugo, Arias, Guillén, \& Vicente, 2014). The development of the SIS-C in Spanish has been successfully developed according to the seven-step process proposed by Tassé and Craig (1999) as required to effectively adapt items to any context different from the original: (1) 
translation/adaptation; (2) consolidation of translation/adaptation; (3) validation of preliminary translation; (4) revisions/adjustments; (5) pilot testing; (6) revisions/adjustments; and (7) field testing validation.

The aim of this paper is to describe an empirical study focused on examining the internal factor structure of the support needs construct as measured by the Spanish version of the SIS-C. Regarding the same structures previously analyzed in the Spanish version of the SIS-A (Verdugo et al., 2007), three factor solutions are defined and tested by a Confirmatory Factor Analysis (CFA): (1) support needs is a unidimensional construct; (2) support needs consists of sevencorrelated factors; and (3) support needs can be understood through a hierarchical model with one second-order factor created by seven subscales of the SIS-C.

\section{Method}

\subsection{Instrument}

The SIS-C (Thompson, Wehmeyer et al., in press) is a measure designed to determine the profile and intensity of the support needs of children with intellectual disability. It was originally developed by the AAIDD and it is nowadays being translated in different languages in a manner parallel to validation of the original version.

This assessment scale has been developed according to the characteristics of the SIS for adults (Thompson et al., 2004) and based on the assumptions of the new socio-ecological concept of intellectual disability (Schalock et al., 2010). The aim of developing this scale for children and adolescents (5-16 years old) is to allow the assessment of individualized support needs at an early age to facilitate provision of individualized support and improve the quality of life of people with intellectual disability since their childhood. 
The SIS-C is divided into two main sections and accompanied by an instruction document, which includes information about the support needs construct, its evaluation, and some examples of its items. Section I describes a set of 32 items (ranged from 0 to 2 ) that includes potential extraordinary support needs (18 medical and 14 behavioral support needs) that may influence a person's support needs. Section II deals with the assessment of the support needs construct and includes a pool of 61 items, divided into seven domains, which reflect the different activities of any child's daily life. The intensity profile and the index of the person assessed are drawn from the scores obtained in this final part of the scale. Specifically, each activity is ranked from 0 to 4 according to three indices (type, frequency, and daily time of the support needed) and the items score is generated by the sum of the scores for each index. To provide better understanding of the SIS-C, below we present two Tables (1-2) showing the characteristics of this section and describing both its domains and response format.

Table 1. SIS-C domains

\begin{tabular}{llc}
\hline SIS-C Domains & Description & \multicolumn{1}{c}{$\begin{array}{c}\text { Number of } \\
\text { Items (61) }\end{array}$} \\
\hline A. Home Life & Activities completed as a function of living in a household. & 9 \\
$\begin{array}{l}\text { B. Community \& } \\
\text { Neighborhood Living }\end{array}$ & $\begin{array}{l}\text { Activities completed as a function of being a member of a } \\
\text { community or neighborhood. }\end{array}$ & 8 \\
C. School Participation & $\begin{array}{l}\text { Activities associated with participating in the school } \\
\text { community. }\end{array}$ & 9 \\
D. School Learning & $\begin{array}{l}\text { Activities associated with acquiring knowledge and/or skills } \\
\text { while attending school. }\end{array}$ & 9 \\
E. Health \& Safety & $\begin{array}{l}\text { Activities that assure health and safety across home, school, } \\
\text { and community environments. }\end{array}$ & 9 \\
F. Social & $\begin{array}{l}\text { Activities that pertain to social integration with other, both } \\
\text { children and adults. }\end{array}$ \\
G. Advocacy & $\begin{array}{l}\text { Activities related to acting as a causal agent in one's life, } \\
\text { making choices and decisions, and availing oneself of } \\
\text { leadership opportunities. }\end{array}$ \\
\hline
\end{tabular}


Table 2. SIS-C rating metric

\begin{tabular}{|c|c|c|}
\hline $\begin{array}{l}\text { TYPE OF } \\
\text { SUPPORT }\end{array}$ & FRECUENCY OF SUPPORT & $\begin{array}{l}\text { DAILY TIME OF } \\
\text { SUPPORT }\end{array}$ \\
\hline 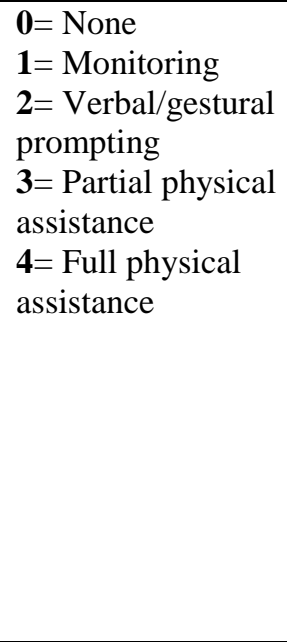 & 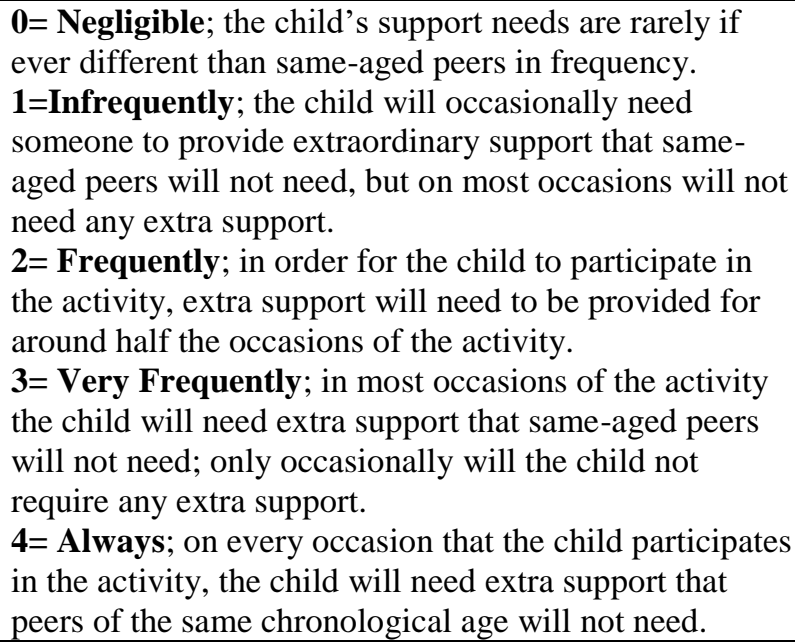 & $\begin{array}{l}\mathbf{0}=\text { None } \\
\mathbf{1}=\text { Less than } 30 \\
\text { minutes } \\
\mathbf{2}=30 \text { minutes to less } \\
\text { than } 2 \text { hours } \\
\mathbf{3}=2 \text { hours to less } \\
\text { than } 4 \text { hours } \\
\mathbf{4}=4 \text { hours or more }\end{array}$ \\
\hline
\end{tabular}

As described by Seo et al. (in press), although the SIS-C is based on the SIS-A, adjustments were carried out to make the instrument's items more appropriate for children and young people. Specifically, two activity domains in the SIS-A (Employment and Lifelong Learning) were replaced in the SIS-C with more age-appropriate distinct activity domains (School Participation and School Learning), and the Advocacy domain was included in the main part of the scale. Similarly, some of the items included in the parallel domains across SIS-A and SIS-C were modified to accurately reflect differences in the environmental demands associated with the new age group (e.g. in the Home Life domain, 'Housekeeping and cleaning' on the SISA was modified to 'Performing household chores' on the SIS-C).

Moreover, additional modifications were made to the rating scale for frequency on the SIS-C to improve how this aspect worked. On the SIS-A a five-point scale was also used, but the descriptions of each category were different: $0=$ none or less than monthly; $1=$ at least once a month, but not once a week; 2 = at least once a week, but not once a day; $3=$ at least once a day, but not once an hour; $4=$ hourly or more frequently. 
However, the SIS-C also has many aspects in common with the SIS-A, including the administration procedure. Although some studies criticize the SIS because requires respondents to estimate support needs for activities that a person has not yet had an opportunity (Riches et al., 2009b), which causes confusion for the informants, this aspect was not changed in the SIS-C. Thompson and Viriyangkura (2013) highlighted that the scale should be administered by a trained interviewer to guide the estimation process. The authors also argued that moving respondents out of their comfort zone and forcing them to envision people engaged in a variety of life activities in the community are useful byproducts of this tool assessment process.

\subsection{Participants}

Participants were selected using non-probabilistic and incidental sampling due to the practical impossibility of random sampling when working with people, as these cases require the express consent of those involved in the evaluations. In any case, a minimum number of 600 participants was set, ensuring that the number of participants was at least 10 times greater than the number of the items (61). A letter was sent to numerous organizations and schools in Spain to recruit the required number of participants. A notice was also posted on the Institute of Community Integration at the University of Salamanca (INICO) website requesting voluntary cooperation. After initial contact, all the professionals who expressed interest and agreed to participate in our project received a formal letter and an informed consent form, which had to be voluntarily signed by the families of all of the children (5-16 years old) with intellectual disabilities who were to be assessed. Finally, more than 50 organizations and schools (mostly special schools, 60.6\%) from 11 different Autonomous Communities in Spain participated in the study, and a total of 833 evaluations were performed. After eliminating all the cases in which there were missing data, 814 evaluations were analyzed. 
Demographic information about all the people involved in the assessment was gathered through an initial questionnaire included on the cover page of the scale. The participants were all Caucasian and born in Spain. As far as age is concerned, all the subjects were between 5 and 16 years old $(M=11.15 ; S D=3.44)$ and had already been diagnosed as having mild, moderate, severe or profound intellectual disability, as these characteristics were required for participation in the study. Other useful information about the socio-demographic characteristics of the children assessed is presented in Table 3 .

Table 3. Demographic characteristics of the sample $(n=814)$

\begin{tabular}{|c|c|c|c|c|c|}
\hline VARIABLES & $N$ & $\%$ & VARIABLES & $N$ & $\%$ \\
\hline Gender & & & Scholar setting & & \\
\hline Male & 528 & 64.6 & Private & 550 & 67.5 \\
\hline Female & 286 & 35.1 & Public & 252 & 31.0 \\
\hline Missing Data & 3 & 0.4 & Missing Data & 12 & 1.5 \\
\hline Total & 814 & 100 & Total & 814 & 100 \\
\hline Age & & & Home Residence & & \\
\hline 5-6 years old & 110 & 13.5 & Family Home & 778 & 95.6 \\
\hline $7-8$ years old & 108 & 13.3 & Foster Family Home & 9 & 1.1 \\
\hline $9-10$ years old & 100 & 12.3 & Small Group Home $(<7)$ & 7 & 0.9 \\
\hline 11-12 years old & 148 & 18.2 & Midsize Group home (7-15) & 9 & 1.1 \\
\hline $13-14$ years old & 195 & 24.0 & Large Residential Facility $(>15)$ & 3 & 0.4 \\
\hline $15-16$ years old & 153 & 18.8 & Missing Data & 11 & 1.4 \\
\hline Total & 814 & 100 & Total & 814 & 100 \\
\hline Intellectual Disability Level & & & Primary Language Understood & & \\
\hline Mild & 206 & 25.3 & Castilian & 784 & 96.3 \\
\hline Moderate & 290 & 35.6 & Catalan, Basque, Galician, Sign Lang. & 14 & 1.8 \\
\hline Severe & 195 & 24.0 & Arabic & 3 & 0.4 \\
\hline Profound & 65 & 8.0 & Others (English, Romanian...) & 3 & 0.4 \\
\hline Missing Data & 58 & 7.1 & Missing Data & 9 & 1.1 \\
\hline Total & 814 & 100 & Total & 814 & 100 \\
\hline Etiology & & & Presence of Other Disabilities & & \\
\hline Non-Specific & 317 & 38.6 & None & 281 & 34.5 \\
\hline Down syndrome & 111 & 13.6 & Physical & 33 & 4.1 \\
\hline Autism Spectrum Disorder & 248 & 30.5 & Sensory & 17 & 2.1 \\
\hline Cerebral Palsy & 101 & 12.4 & Language & 211 & 25.9 \\
\hline Rare diseases & 35 & 4.3 & Other (Mental Health...) & 82 & 10.1 \\
\hline Co-occurrence & 5 & 0.6 & Two or more & 190 & 23.3 \\
\hline Total & 814 & 100 & Total & 814 & 100 \\
\hline Type of classroom placement & & & Assistive Technologies Use & & \\
\hline Regular classes in regular schools & 179 & 22.0 & Yes & 155 & 19.1 \\
\hline Special classes in special schools & 493 & 60.5 & No & 657 & 80.7 \\
\hline $\begin{array}{l}\text { Special classes in regular schools } \\
\text { Others }\end{array}$ & $\begin{array}{l}55 \\
87\end{array}$ & $\begin{array}{r}6.8 \\
107\end{array}$ & Missing Data & 2 & 0.2 \\
\hline Total & 814 & 100 & Total & 814 & 100 \\
\hline
\end{tabular}


The assessment was not carried out directly on the child being assessed but instead was based on the judgment of other respondents who knew the assessed child very well and had had the opportunity to observe their behavior in various natural settings over an extended period of time. According to the requirements in administering the SIS-C, the collaboration of two respondents who are very familiar with the assessed person was inquired. A second respondent collaborated on the information gathering in 661 of the assessments $(81.2 \%)$

Specifically, 783 of the 814 main respondents were direct-care professionals $(96.3 \%)$ and 31 were relatives $(3.7 \%)$. Considering the second respondent, $65.7 \%$ were relatives and $37.3 \%$ were other direct-care professionals. The instrument was administered by qualified professionals trained through a previous session given by the research team (37\%) or by an interviewer from the research team $(63 \%)$.

\subsection{Data Analysis}

A Confirmatory Factor Analysis (CFA) was carried out to determine the SIS-C factor structure. The LISREL program [version 8.8] (Jöreskog \& Sörbom, 2006) was used for this analysis.

CFA is included within Structural Equation Modeling (SEM) and allows us to determine, through goodness-of-fit indices, whether data is consistent with the theoretical models related to the psychological construct assessed. Therefore, it was necessary to identify and specify the models before performing the analysis to ensure more relevant hypotheses about the nature of this construct were included and that our data met the criteria required to carry out a CFA. So as to reduce model complexity (the SIS-C comprises more than 60 items), parcels were created as indicators of a latent construct by combining individual items and using them as observed variables. 


\section{Results}

\subsection{Preparing the data: Use of parcels}

Taking into account the aim of our study was to examine of the relations among latent variables assessed and that the SIS-C is composed of more than 60 indicators, the items of the SIS-C were divided into 21 unidimensional parcels averaging groups of two or three items (Table 4) and following the same correlative method used in the SIS-A analyses (Verdugo, Arias, \& Ibañez, 2007). Although using parcels could limit data analysis (e.g., parcels may mask model misspecifications and the interpretation of what constitutes the construct can be muddied), its disadvantages are reduced if parcel application is well-informed as well as making sure of the parcels' unidimensionality (Little, Rhemtulla, Gibson, \& Schoemann, 2013). Following the recommendations of Courntey (2013), we used both absolute and relative criteria to assure the unidimensionality of each parcel: (a) just the first component had an eigenvalue greater than 1 ; (b) the eigenvalue of the first factor extracted was four times higher than the eigenvalue of the second factor; (c) the percentage of variance explained by the first factor was greater than $60 \%$; and (d) the difference between the proportion of variance explained by the first and second factors was higher than 40 .

Table 4. Parcels creation and unidimensionality

\begin{tabular}{|c|c|c|c|c|c|c|c|c|}
\hline \multirow[b]{2}{*}{ Domains } & \multirow[b]{2}{*}{ Parcels } & \multirow[b]{2}{*}{ Items } & \multirow[b]{2}{*}{ Mean } & \multirow[b]{2}{*}{$\begin{array}{c}\text { Standard } \\
\text { Deviation }\end{array}$} & \multicolumn{4}{|c|}{ PARCELS UNIDIMENSIONALITY } \\
\hline & & & & & $\begin{array}{c}\text { Eigenvalue } \\
1\end{array}$ & $\begin{array}{c}\text { Eigenvalue } \\
2\end{array}$ & $\begin{array}{c}\text { Explained } \\
\text { Variance E1 } \\
(\%) \\
\end{array}$ & $\begin{array}{c}\text { Explained } \\
\text { Variance E2 } \\
(\%) \\
\end{array}$ \\
\hline \multirow{3}{*}{ A. Home Life } & P_A1 & $\mathrm{A} 1, \mathrm{~A} 2, \mathrm{~A} 3$ & 6.65 & 3.33 & 2.55 & .29 & 85.01 & 9.75 \\
\hline & P_A2 & $\mathrm{A} 4, \mathrm{~A} 5, \mathrm{~A} 6$ & 5.24 & 3.54 & 2.50 & .35 & 83.43 & 11.83 \\
\hline & P_A3 & $\mathrm{A} 7, \mathrm{~A} 8, \mathrm{~A} 9$ & 6.21 & 3.64 & 2.51 & .24 & 83.97 & 08.10 \\
\hline \multirow{3}{*}{$\begin{array}{l}\text { B. Community \& } \\
\text { Neighborhood } \\
\text { Living }\end{array}$} & P_B1 & $\mathrm{B} 1, \mathrm{~B} 2, \mathrm{~B} 3$ & 7.33 & 3.30 & 2.62 & .21 & 87.49 & 7.28 \\
\hline & P_B2 & $\mathrm{B} 4, \mathrm{~B} 5, \mathrm{~B} 6$ & 7.74 & 3.03 & 2.63 & .20 & 87.77 & 6.91 \\
\hline & P_B3 & B7, B8 & 7.45 & 3.36 & 1.77 & .22 & 88.92 & 11.07 \\
\hline \multirow{3}{*}{$\begin{array}{l}\text { C. School } \\
\text { Participation }\end{array}$} & $\mathrm{P} \_\mathrm{C} 1$ & $\mathrm{C} 1, \mathrm{C} 2, \mathrm{C} 3$ & 7.90 & 3.22 & 2.52 & .33 & 84.27 & 11.18 \\
\hline & P_C2 & $\mathrm{C} 4, \mathrm{C} 5, \mathrm{C} 6$ & 7.43 & 3.08 & 2.27 & .44 & 75.79 & 14.81 \\
\hline & P_C3 & $\mathrm{C} 7, \mathrm{C} 8, \mathrm{C} 9$ & 6.74 & 3.77 & 2.68 & .24 & 89.36 & 9.06 \\
\hline
\end{tabular}




\begin{tabular}{|c|c|c|c|c|c|c|c|c|}
\hline \multirow{3}{*}{$\begin{array}{l}\text { D. School } \\
\text { Learning }\end{array}$} & P_D1 & D1, D2, D3 & 9.72 & 2.52 & 2.69 & .17 & 89.69 & 5.87 \\
\hline & P_D2 & D4, D5, D6 & 8.89 & 2.77 & 2.59 & .22 & 86.38 & 7.32 \\
\hline & P_D3 & D7, D8, D9 & 8.67 & 2.75 & 2.47 & .27 & 82.61 & 9.14 \\
\hline \multirow{3}{*}{$\begin{array}{l}\text { E. Health \& } \\
\text { Safety }\end{array}$} & P_E1 & E1, E2, E3 & 7.21 & 3.30 & 2.46 & .27 & 82.16 & 9.10 \\
\hline & P_E2 & E4, E5, E6 & 8.15 & 3.01 & 2.54 & .28 & 84.89 & 9.63 \\
\hline & P_E3 & E7, E8 & 8.11 & 3.28 & 1.79 & .20 & 89.60 & 10.39 \\
\hline \multirow{3}{*}{ F. Social } & P_F1 & $\mathrm{F} 1, \mathrm{~F} 2, \mathrm{~F} 3$ & 7.21 & 3.47 & 2.48 & .33 & 82.81 & 11.27 \\
\hline & P_F2 & $\mathrm{F} 4, \mathrm{~F} 5, \mathrm{~F} 6$ & 7.64 & 3.22 & 2.43 & .34 & 81.16 & 11.60 \\
\hline & P_F3 & F7, F8, F9 & 7.48 & 3.35 & 2.34 & .38 & 78.17 & 12.97 \\
\hline \multirow{3}{*}{ G. Advocacy } & P_G1 & G1, G2, G3 & 7.77 & 3.10 & 2.50 & .41 & 83.50 & 13.74 \\
\hline & P_G2 & G4, G5, G6 & 7.97 & 3.18 & 2.59 & .23 & 86.53 & 7.74 \\
\hline & P_G3 & G7, G8, G9 & 8.06 & 3.12 & 2.51 & .30 & 83.67 & 10.26 \\
\hline
\end{tabular}

Finally, related to the suitability of each parcel as part of a CFA, we also analyzed the Kaiser-Meyer-Olkin (KMO) index (Kaiser, 1970) and Barlett's test of sphericity (Barlett, 1954). KMO results were higher than 0.5 (inferior limit) and the values obtained in the Barlett's test were significant $(p<.001)$, as expected.

\subsection{Specification and identification of the models}

According to the SIS literature, support needs are explained by a correlational model (i.e., SIS domains are first-order factors that correlate with one another) in the original version (Thompson et al., 2004) and its adaptations to other countries (e.g., Kuppens et al., 2010), including Spain (Verdugo et al., 2007), where there were also some attempts to confirm a higherorder factor model. However, other studies showed that a unidimensional approach to the construct fits SIS data (Harries, Guscia, Kirby, Netttelbeck, \& Taplin, 2005). Considering the three previous perspectives of the support needs construct, we designed three hypotheses for the structure of the SIS-C (Table 5).

Moreover, in order to carry out a confirmatory analysis (Arias, 2008; Kline, 2010), it is needed to ensure that the models analyzed are over-identified (positive $d f$ ), which means that there should be more observations than parameters to be estimated. In our data, we obtained 231 
observations ( 21 variances and 210 covariances). The number of parameters to be estimated depends on each model tested (Table 5). According to the common method of setting the scale of latent variables, one path from each latent variable was set to 1 (Unit Loading Identification, ULI).

Table 5. Models tested by CFA

\begin{tabular}{|c|c|c|c|}
\hline \multicolumn{3}{|c|}{ MODEL SPECIFICATION } & \multirow[b]{2}{*}{ MODEL IDENTIFICATION } \\
\hline Hypothesis & $\begin{array}{c}\text { Factors } \\
\text { Number }\end{array}$ & Description & \\
\hline $\begin{array}{l}\text { H1.Unidimensional } \\
\text { Model }\end{array}$ & 1 & $\begin{array}{l}\text { 'Support needs' is } \\
\text { explained by one factor } \\
\text { (Support Needs) }\end{array}$ & $\begin{array}{l}\text { Over-identified Model }(189 \mathrm{df}) \\
231 \text { observed variables minus } 42 \text { parameters } \\
\text { to estimate ( } 21 \text { measurement error variances } \\
\text { od the indicators; } 1 \text { factor variance; and } 20 \\
\text { direct effects). }\end{array}$ \\
\hline $\begin{array}{l}\text { H2. Correlated } \\
\text { First-Order } \\
\text { Factors Model }\end{array}$ & 7 & $\begin{array}{l}\text { 'Support needs' consists of } \\
\text { correlated factors } \\
\text { ( } 7 \text { subscales of the SIS-C) }\end{array}$ & $\begin{array}{l}\text { Over-identified Model }(168 d f) \\
231 \text { observed variables minus } 63 \text { parameters } \\
\text { to estimate ( } 21 \text { measurement error variances } \\
\text { of the indicators; } 7 \text { factor variances; } 21 \text { factor } \\
\text { covariances; and } 14 \text { direct effects of the } \\
\text { factors on the indicators). }\end{array}$ \\
\hline $\begin{array}{l}\text { H3.Higher-Order } \\
\text { Factor Model }\end{array}$ & 8 & $\begin{array}{l}\text { 'Support needs' consists } \\
\text { of correlated factors } \\
\text { ( } 1 \text { second-order factor } \\
\text { created by seven subscales } \\
\text { of the SIS-C) }\end{array}$ & $\begin{array}{l}\text { Over-identified Model }(182 \mathrm{df}) \\
231 \text { observed variables minus } 49 \text { parameters } \\
\text { to estimate ( } 21 \text { measurement error variances } \\
\text { of the indicators; } 7 \text { measurement error } \\
\text { variances of the endogenous variables, } 1 \\
\text { exogenous variable variance, } 14 \text { direct effects } \\
\text { of the endogenous variables on the indicators; } \\
\text { and } 6 \text { direct effects of the exogenous variable } \\
\text { on the endogenous variables). }\end{array}$ \\
\hline
\end{tabular}

\subsection{Parameter estimation and model fit}

The term parameter estimation refers to the process of using sample data to estimate the parameters of the selected distribution. Our hypotheses state that there will be no significant differences between the sample variance-covariance matrix and the variance-covariance matrix estimated by each model. Although using parcels improves the data's properties in terms of normality, it was not possible to arrive at the univariate normality. Consequently, the multivariate normality needed to use Maximum Likelihood estimation procedures was rejected $(\mathrm{p}<.001)$ when it was tested through the procedures of Mardia (1970). 
In the cases in which the assumption of normality is severely violated, the Diagonally Weighted Least Squares (DWLS) method provides more accurate parameter estimates (Arias, 2008). The DWLS belongs to the robust WLS methods but only uses the diagonal of weights, reducing the amount of data needed. The DWLS method is based on the polychoric variancescovariances matrix and the estimation of asymptotic covariances. The standardized solution for the three models (Figures 1-3) is set out below.

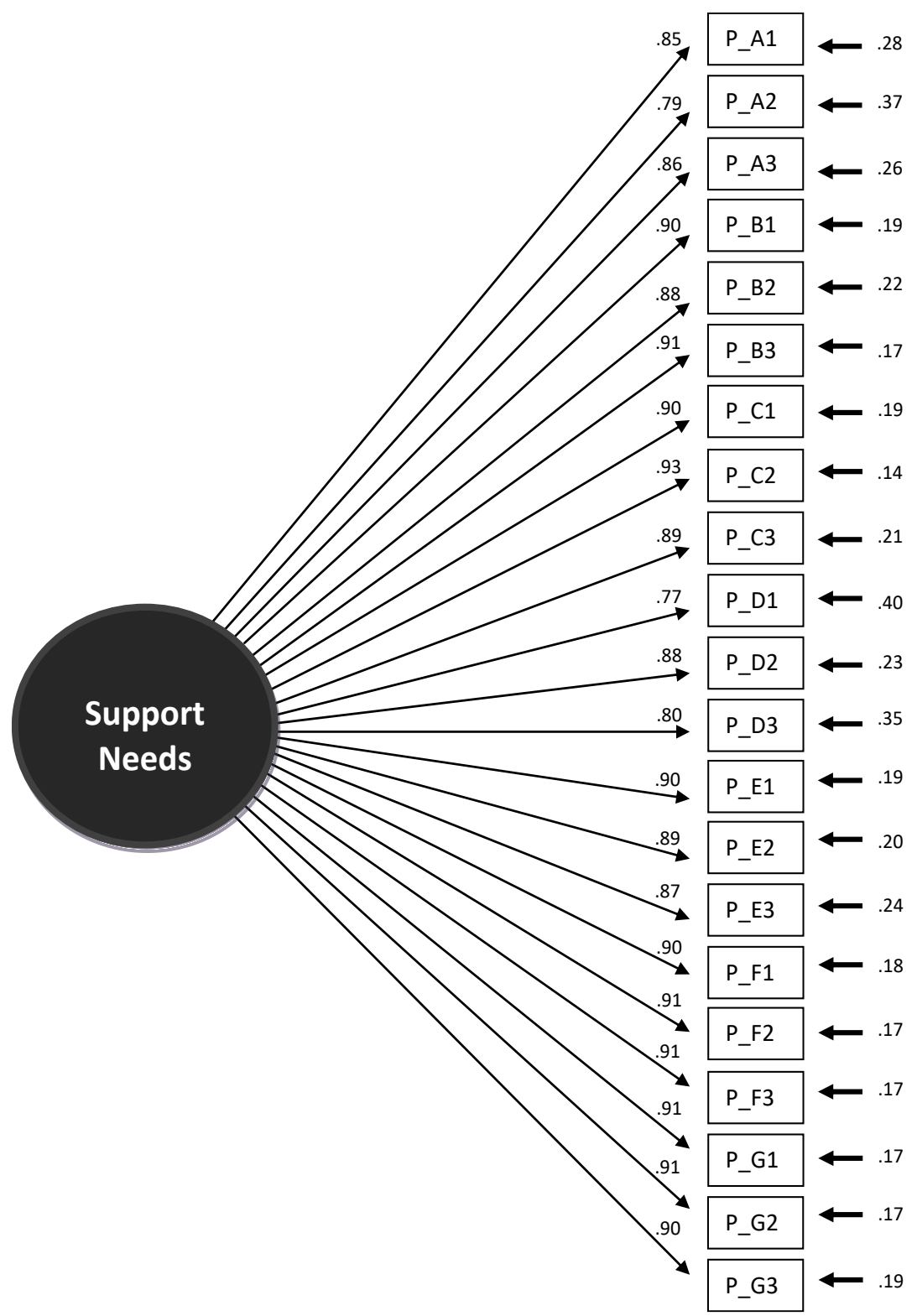

Figure 1. Standardized solution for the factorial representation of the unidimensional model (H1) 
In the first solution, for the unidimensional model, we noticed that the measurement error ranged between .14 (P_C2) and .40 (P_D1). It was thus deduced that the squared coefficient of multiple correlation or the amount of variance explained by the latent variable fell within a range of between .86 and .60. Similarly, all the factor loadings had values equal to or greater than .77 .

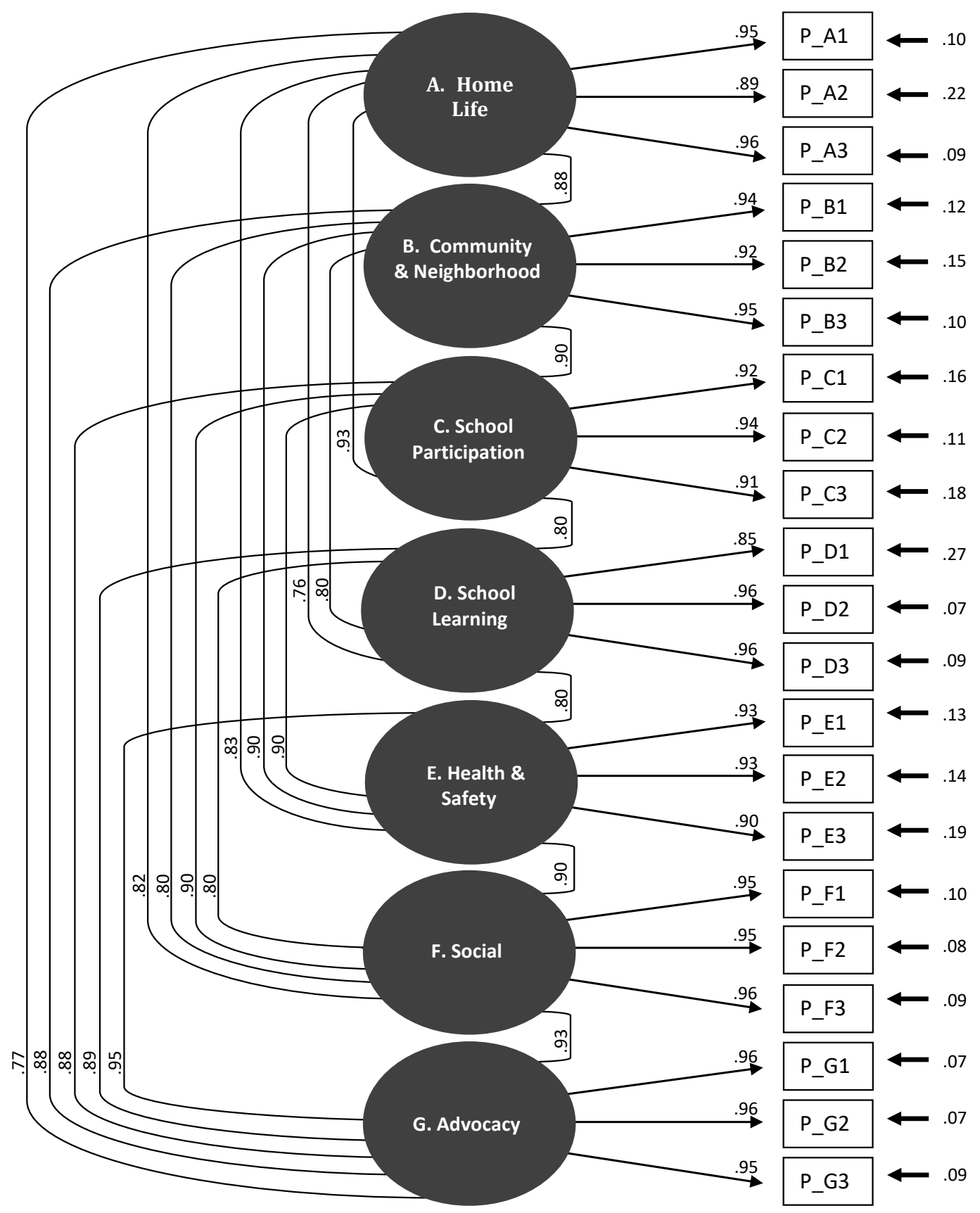

Figure 1. Standardized solution for the factorial representation of the correlated first-order factors (H2) 
In the second solution, corresponding to the correlated first-order factors model, we noticed that the measurement error ranged between .07 (P_D2; P_G1; P_G2) and .27 (P_D1). It was thus deduced that the squared coefficient of multiple correlation or the amount of variance explained by the latent variables ranged between .93 and .73 . The correlations between latent constructs ranged between .76 and .95 . All the factor loadings had values equal to or greater than .85 .

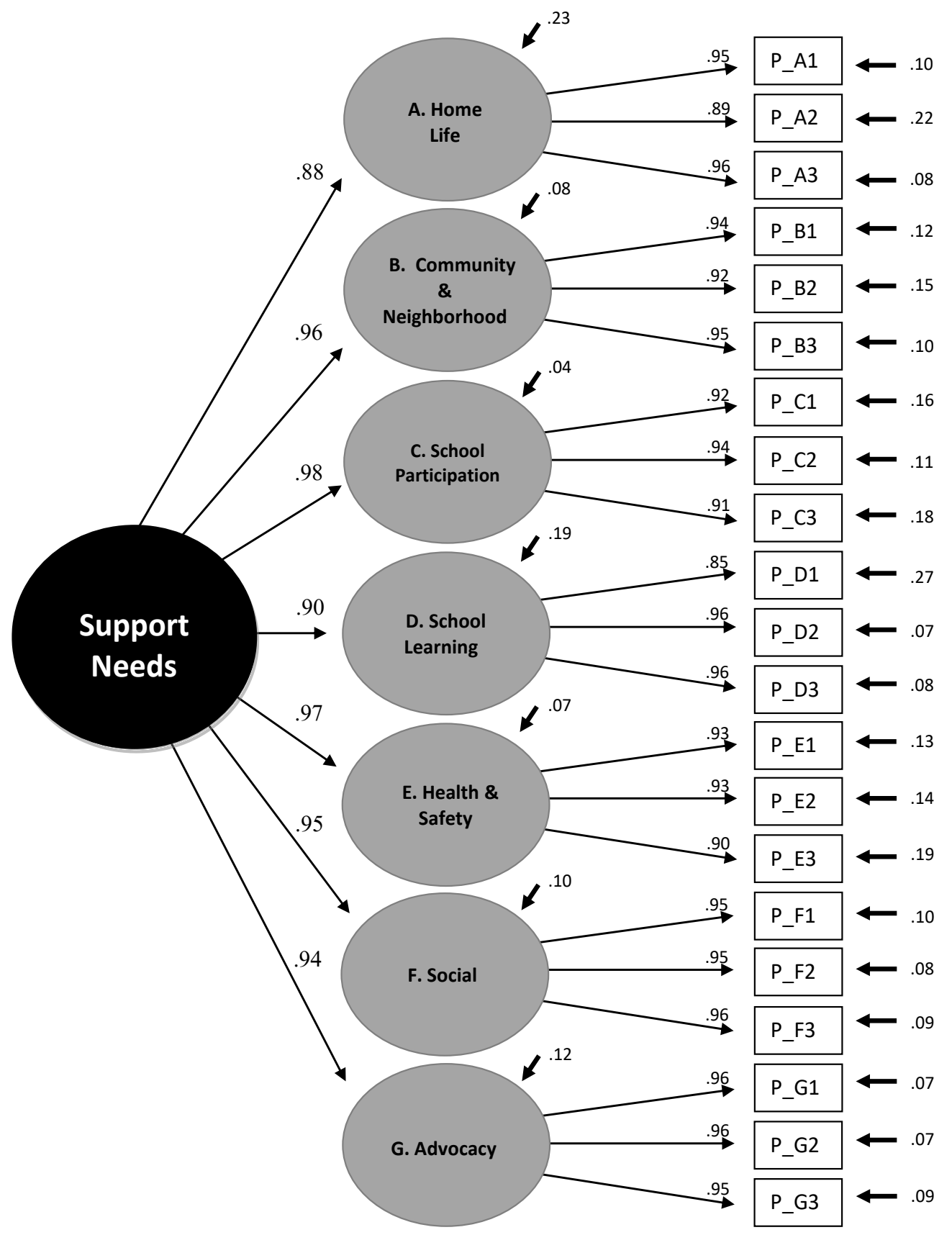

Figure 3. Standardized solution for the factorial representation of the higher-order factor model (H3) 
The higher-order model showed that the measurement error for the parcels ranged between .07 (P_D2; P_G1; P_G2) and .27 (P_D1). It was thus deduced that the squared coefficient of multiple correlation or the amount of variance explained by the endogenous variables ranged between .93 and .73 . Similarly, the residual variance for the endogenous variables ranged between .04 (C. School Participation) and .23 (A. Home Life) and the amount of variance explained by the exogenous variable ranged between .96 and .77 . All the factor loadings had values equal to or greater than .88 .

Once the parameters had been estimated, we analyzed both absolute and partial goodness-of-fit indices for each model (Table 6). The absolute index used for verifying the null hypothesis was the Chi-Square Index $\left(\chi^{2}\right)$. When we analyzed the values shown by the models, we had to reject the null hypothesis in all cases $(p<.001)$, however, this criterion is often unmet when working with a large sample (Hu \& Bentler, 1999). In these cases it is recommended to take into account the $\chi^{2}$ magnitude (considering a better fit when smaller) and other common partial indices (Arias, 2008; Kline, 2010): (a) Root Mean Square error of Approximation (RSMEA); (b) Tucker-Lewis Index (TLI); (c) Comparative Fit Index (CFI); and (d) Standardized Root Mean Square Residual (SRMR).

Table 6. Goodness-of-fit indices

\begin{tabular}{|c|c|c|c|c|}
\hline FIT INDICES & INTERPRETATION & $\begin{array}{c}\text { Unidimensional } \\
\text { Model }(\mathrm{H} 1)\end{array}$ & $\begin{array}{l}\text { Correlated First- } \\
\text { Order Factors } \\
\text { Model }(\mathrm{H} 2) \\
\end{array}$ & $\begin{array}{c}\text { Higher-Order } \\
\text { Factor Model } \\
\text { (H3) }\end{array}$ \\
\hline$\chi^{2}(d f)$ & \multirow{2}{*}{ To accept $H_{0}(p>.01)$} & $4625.11(189)$ & $981.57(168)$ & $1402.92(182)$ \\
\hline$p$ & & $<.001$ & $<.001$ & $<.001$ \\
\hline$R M S E A$ & \multirow{2}{*}{$\begin{array}{l}\text { Acceptable values until } .08 \text {. } \\
\text { Other values lower than } .10 \\
\text { could be accepted. }\end{array}$} & .17 & .077 & .091 \\
\hline RMSEA (90\%) & & $(.17-.17)$ & $(.073-.082)$ & $(.086-.095)$ \\
\hline$T L I$ & It should be higher than .95 & .95 & .99 & .99 \\
\hline
\end{tabular}




\begin{tabular}{lllll}
\hline CFI & It should be higher than .95 & .96 & .99 & .99 \\
\hline SRMR & $\begin{array}{l}\text { Values less than } .05 \text { show a } \\
\text { good fit }\end{array}$ & .047 & .020 & .033 \\
\hline
\end{tabular}

These findings clearly show that the data obtained by administering the SIS-C do not fit the first hypothesis (unidimensional model). On the other hand, there were good results for both the correlated first-order factors and the higher-order factor hypotheses when partial indices were taken into account. In view of these results, it is necessary to analyze which of the two models has a better model fit.

Satorra and Bentler (2001) proposed conducting a specific corrected Chi-Square difference test in order to analyze nested models when data presents a lack of normality. The results obtained $\left(\chi_{d}^{2}=423.65 ; d f=14 ; p<.001\right)$ showed significant differences, allowing us to reject the null hypothesis and conclude that the model that presents lower RSMEA and SRMR values and a smaller Chi-Square (i.e., the correlated first-order factors model) is significantly better than the comparison model (i.e., the higher-order factor model).

Although it was shown that the correlated first-order factors model was the best solution to represent the factorial structure of the scale, the multicollinearity or the high correlations found between some of the factors can affect discriminant validity. To determine the degree of multicollinearity, we computed the Variance Inflation Factor (VIF) for each independent variable. VIF values did not exceed the value of 10 , which is often regarded as indicating severe multicollinearity (Neter, Kutner, Nachtsheim, \& Wasserman, 1996).

At this point, the model's consistency was tested. For each of the seven latent variables, we analyzed both the composite reliability $\left(\rho_{c}\right)$, which indicates the overall reliability of a collection of heterogeneous but similar items within underlying traits; and the average variance 
extracted $\left(\rho_{v}\right)$, which indicates how accurately the construct is measured. Values should be greater than .50 (Hair, Ringle, \& Sarstedt, 2011). As one can see in Table 7, both indices were within a satisfactory range $(>.70)$.

Table 7. Composite reliability an average variance extracted of the correlational model

\begin{tabular}{lcc}
\hline DOMAINS & $\rho_{C}=\frac{(\Sigma \lambda)^{2}}{(\Sigma \lambda)^{2}+\Sigma(\theta)}$ & $\rho_{V}=\frac{\left(\Sigma \lambda^{2}\right)}{\left[\Sigma \lambda^{2}+\Sigma(\theta)\right]}$ \\
\hline A. Home Life & .950 & .865 \\
B. Community \& Neighborhood Living & .948 & .858 \\
C. School Participation & .957 & .880 \\
D. School Learning & .955 & .877 \\
E. Health \& Safety & .950 & .864 \\
F. Social & .955 & .877 \\
G. Advocacy & .945 & .850 \\
\hline
\end{tabular}

\section{Discussion}

The SIS-C is the first attempt to assess support needs in children with intellectual disability within the Spanish context and the main tool to gain knowledge on the support needs construct from a childhood perspective. In this paper, a study of the internal structure of this instrument was carried out using a CFA to analyze the nature of the construct and reveal thus how the SIS-C should be scored.

The scale's structures that were tested were those previously analyzed in different research on the SIS-A (e.g., Harries et al., 2005; Kuppens, et al., 2010; Thompson et al., 2004; Verdugo et al., 2007): (1) support needs is a unidimensional construct; (2) support needs is a correlated firstorder factors construct; (3) support needs is a higher-order factor construct. Goodness-of-fit analysis showed that a single domain was not enough to reproduce the original matrix and explain the nature of support needs. However, this construct seemed to be multidimensional according to fit indices. Specifically, the correlated first-order factors model was best suited. CFA findings of 
multidimensionality potentially have important applied consequences in term of scale scoring an interpretation. Although it does not necessarily mean that a total scale score is an inadequate indicator of the intended construct, subscales might not be interchangeable indicators of a single construct, which have distinct implications for health policy and psychological intervention (Reise, Bonifay, \& Haviland, 2013).

These findings confirm the correlational model obtained from the SIS structure (Kuppens, et al., 2010; Thompson et al., 2004; Verdugo et al., 2007) providing initial evidence of the pattern of this construct in childhood. It is important to note that the correlational factor structure found in the SIS-C includes the domain 'Advocacy', which was considered a supplementary subscale in the SIS-A and was not included as part of the main model obtained. However, due to its special interest in the transition to adulthood and the consistency shown by this subscale in recent studies (Shogren et al., 2014), the relevance of including this domain as part of the support needs index and profile is assured.

The SIS-C, as well as the SIS-A, will be useful in designing intervention strategies adapted to the individual characteristics of the participants, evaluating the functioning improvements achieved through the implementation of ISP (Thompson et al., 2009); and, ultimately, implementing evidence-based practices (Schalock, Verdugo, \& Gómez, 2011). Furthermore, these instruments tackle the challenge of requiring assessors to envision people with ID engaged in a variety of ordinary life activities, including those in which they might not have the opportunity to participate regularly (Thompson \& Viriyangkura, 2013). Use of this scale leaves behind the traditional focus on intellectual deficit and starts from a position of interest in human strengths and their development through the support provided by the social context, which can be easily framed within 'positive psychology' (Schalock, 2004). 
Additionally, SIS-C provides an element of added value in that it can be incorporated into school environments and help teachers to provide individualized support in a diverse range of academic and non-academic activities, promoting the rights and inclusion of children with intellectual and developmental disabilities.

Despite the various useful implications of this work, some limitations must be identified. Firstly, this study involves an incidental sample, which does not ensure representativeness. Taking into account this limitation, the research team worked to achieve a large number of participants $(n=814)$, increasing the chances that a diverse range of individuals were sampled, and attempted to obtain an appropriate representation of the population regarding age and intellectual disability level. However, it was not possible to reach the participation of two respondents in all the assessments. Secondly, although a previous session was given by the research team to guarantee that the interviewers were qualified to administrate the SIS-C, the effect of interviewers on data was not analyzed (e.g., inter-interviewer reliability). Thirdly, the children were classified into the different types of disability and into the specific categories of intellectual disability (mild, moderate, severe and profound) on the basis of the clinical judgment of professionals from the collaborating centers when an objective evaluation was not available. Another limitation worth pointing out is that parcels (not items) were used as indicators in the CFA. Although the use of parcels is appropriate for this study, it may be one of the reasons why the models fit so closely. Moreover, item-level analyses were not conducted, so it is difficult to know how well individual items were related to the latent trait of interest.

Finally, although the correlated first-order factors model produces suitable goodness-offit indices, and composite reliability and average variance extracted indicate that each subscale is by itself a reliable factor without needing to turn to a higher-order factor model, we would like to 
remark the high correlations found between some of the first-order factors, which could affect discriminant validity. Although VIF values did not indicate severe multicollinearity, it would be relevant to check other factorial solutions, which could help address concerns about the internal structure of the support needs construct when measured in childhood.

In this context, the use of more complicated, multidimensional latent variable model specifications, such as second-order or bi-factor measurement models must be considered (Reise et al., 2013). Following the recommendations of these authors, further research should be also conducted to determine the appropriateness of reporting subscales scores. To address this aim, it would be necessary to confirm that: (a) total scale scores are not better estimators of subscales true scores than the subscales scores themselves; and (b) subscales scores provide 'add value' beyond total scores.

Results obtained in this work contribute to the breakthrough in the understanding of the support needs of children with intellectual disability and show construct validity evidences of the SIS-C. However, further research in this field is needed to provide more validity and reliability evidences and ensure the clinical utility of this instrument.

\section{References}

Arias, B. (2008). Desarrollo de un ejemplo de análisis factorial confirmatorio con LISREL, AMOS y SAS. En M. A. Verdugo, M. Crespo, M. Badia, \& B. Arias (Coords.). Metodología en la investigación sobre discapacidad. Introducción al uso de las ecuaciones estructurales (pp. 75-120). Salamanca: INICO.

Arnold, S., Riches, V., \& Stancliffe, R. (2014a). I-CAN: The classification and prediction of support needs. Journal of Applied Research in Intellectual Disabilities, 27(2), 97-111. doi: $10.1111 /$ jar. 12055 
Arnold, S., Riches, V., \& Stancliffe, R. (2014b). Support needs predict funding need better than adaptive behaviour. Journal of Applied Research in Intellectual Disabilities, 27(4), 352.

Bartlett, M. S. (1954). A note on the multiplying factors for various chi square approximations. Journal of Royal Statistical Society, 16(B), 296-298.

Bossaert, G., Kuppens, S., Buntinx, W., Molleman, C., Van Den Abeele, A., \& Maes, B. (2009). Usefulness of the Supports Intensity Scale (SIS) for persons with other than intellectual disabilities. Research in Developmental Disabilities, 30 (6), 1306-1316. doi: 10.1016/j.ridd.2009.05.007

Bruininks, R. H, Hill, B. K, Weatherman, R. F., Woodcock, R. W. (1986) Inventory for client and agency planning (ICAP). Allen, TX: DLM Teaching Resources.

Chou, Y. C., Lee, Y. C., Chang, S. C., \& Yu, A. P. (2013). Evaluating the supports intensity scale as a potential assessment instrument for resource allocation for persons with intellectual disability. Research on Developmental Disabilities, 34(6), 2056-2063. doi: 10.1016/j.ridd.2013.03.013

Colver, A. (2005). A shared framework and language for childhood disability. Developmental Medicine and Child Neurology, 47, 780-784. doi: 10.1017-/S0012162205001635

Courtney, M. G. (2013). Determining the number of factors to retain in EFA: using the SPSS RMenu v2. 0 to make more judicious estimations. Practical Assessment, Research \& Evaluation, 18(8), 1-14.

Cruz, M., Jenaro, C., Pérez, M. C., \& Robaina, N. (2010). Aplicabilidad de la escala de intensidad de apoyos (SIS), en población mexicana con enfermedad mental severa. Revista LatinoAmericana da Enfermagem, 18(5), 975-982.

Fortune, J. Levelle, J., Meche, S., Severance, D., Smith, G., \& Stern, J. (2008). SIS resource allocation: Four papers on issues and approaches. In R. L. Schalock, J. R. \& M. J. Tassé, (Eds.) (2008). AAIDD SIS White Paper Series. Washington, DC: American Association on Intellectual and Developmental Disabilities.

Giné, C., Font, J., Guárdia-Olmos, Balcells-Balcells, A., Valls, J., \& Carbó-Carrete, M. (2014). Using the SIS to better align the funding of residential services to assessed support needs. 
Research in Developmental Disabilities, 35(5), 1144-1151. doi: 10.1016/j.ridd.2014.01.028

Gould, A. (1998). The Service Need Assessment Profile. Version 1.0. [Computer Software and Manual]. Sydney, New South Wales: ATG and associates Pty Ltd.

Guillén, V., Verdugo, M. A., Arias B., \& Vicente, E. (2015). Desarrollo de una escala de evaluación de necesidades de apoyo de niños y adolescentes con discapacidad intelectual [Development of a support needs scale for children and adolescents with intellectual disability]. Anales de Psicología, 31(1), 137-144. doi: 10.6018/analesps.31.1.166491

Guscia, R., Harries, J., Kirby, N., Nettelbeck, T., \& Taplin, J. (2005). Reliability of the Service Need Assessment Profile (SNAP): A measure of support for people with disabilities. Journal of Intellectual and Developmental Disability, 30, 24-30. doi: $10.1080 / 13668250500033144$

Hair, C., Ringle, C. M., \& Sarstedt, M. (2011). PLS-SEM: Indeed a silver bullet. Journal of Marketing Theory and Practice, 19, 139-151.

Harries, J., Guscia, R., Kirby, N., Nettelbeck, T., \& Taplin, J. (2005). Support needs and adaptive behaviors. American Journal on Mental Retardation, 110(5), 393-404. doi: 10.1352/08958017(2005)110[393:SNAAB]2.0.CO;2

Hennike, J. M. (2002). NC-SNAP. Exceptional Parent, 32(9), 56-58.

Hennike, J. M., Myers, A. M., Realon, R. E., \& Thompson, T. (2002). Developmental Disabilities Support Needs Assessment Profile. Butner, NC: Murdoch Centre Foundation.

Hennike, J. M., Myers, A. M., Realon, R. E., \& Thompson, T. (2006). Development and validation of a needs-assessment instrument for persons with developmental disabilities. Journal of Developmental and Physical Disabilities, 18(2), 201-217. doi: 10.1007/s10882-006-9012x

Hu, L., \& Bentler, P. M. (1999). Cutoff criteria for fit indexes in covariance structure analysis: Conventional criteria versus new alternatives. Structural Equation Modeling, 6, 1-55. doi: $10.1080 / 10705519909540118$

Jenaro, C., Cruz, M., Pérez, M. C., Robaina, N., \& Vega, V. (2011). La utilización de la Escala de Intensidad de Apoyos con poblaciones psiquiátricos: Propiedades psicométricas y utilidad 
para la planificación de prestación de servicios. Archives of Psychiatric Nursing, 25(5), 917. doi: 10.1016/j.apnu.2011.05.002.

Jöreskog, K. G., \& Sörbom, D. (2006). LISREL 8.80 for Windows [Computer Software]. Lincolnwood, IL: Scientific Software International, Inc.

Kaiser, H.F. (1970). A second generation Little Jiffy. Psychometrika, 35, 401-415.

Kline, R. B. (2010). Principles and practice of structural equation modeling (3rd ed.). New York: Guilford Press.

Kuppens, S., Bossaert, G., Buntinx, W., Molleman, C., \& van den Abeele, A. (2010). Factorial Validity of the Supports Intensity Scale (SIS). American Journal on Intellectual and Developmental Disabilities, 115, 327-339. doi: 10.1352/1944-7558-115.4.327

Little, T. D., Rhemtulla, M., Gibson, K., \& Schoemann, A. M. (2013). Why the items versus parcels controversy needn't be one. Psychological Methods, 18(3), 285-300. doi: 10.1037/a0033266

Llewellyn, G., Parmenter, T., Chan, J., Riches, V., \& Hindmarsh, G. (2005). I-CAN: Instrument to classify support needs for people with disability. Sydney: The University of Sydney.

Mardia, K.V. (1970). Measures of multivariate skewness and kurtosis with applications. Biometrika, 57, 519- 530.

Neter, J., Kutner, M. H., Nachtsheim, C. J., \& Wasserman, W. (1996). Applied linear statistical models (4th ed.). Boston, MA: McGraw-Hill.

Reise, S. P., Bonifay, W. E., \& Haviland, M. G. (2013). Scoring and modeling psychological measures in the presence of multidimensionality. Journal of personality assessment, 95(2), 129-140.

Riches, V., Parmenter, T., Llewellyn, G., Hindmarsh, G., \& Chan, J. (2009a). I-CAN: A New Instrument to Classify Support Needs for People with Disability: Part I. Journal of Applied Research in Intellectual Disabilities, 22(4), 326-339. doi: 10.1111/j.14683148.2008.00466.x

Riches, V., Parmenter, T., Llewellyn, G., Hindmarsh, G., \& Chan, J. (2009b). The Reliability, Validity and Practical Utility of Measuring Supports using the I-CAN Instrument: Part II. 
Journal of Applied Research in Intellectual Disabilities. 22(4), 340-353. doi: 10.1111/j.1468-3148.2008.00467.x

Satorra, A., \& Bentler, P. M. (2001). A scaled difference chi-square test statistic for moment structure analysis. Psychometrika, 66, 507-514. doi:10.1007/BF02296192

Schalock, R. L. (2004). The emerging disability paradigm and its implications for policy and practice. Journal of Disability Policy Studies, 14, 204-215. doi: $10.1177 / 10442073040140040201$

Schalock, R. L., Borthwick-Duffy, S. A., Bradley, V. J., Buntinx, W. H. E, Coulter, D., Craig, E. M., ...Yeager, M. H. (2010). Intellectual disability: Definition, classification, and systems of supports (11th ed.). Washington, DC: American Association on Intellectual and Developmental Disabilities.

Schalock, R. L., \& Luckasson, R. (2013a). What's at Stake in the Lives of People with Intellectual Disability? Part I: The Power of Naming, Defining, Diagnosing, Classifying, and Planning Supports. Intellectual and Developmental Disabilities, 51, 86-93. doi: 10.1352/1934-955651.2.086

Schalock, R. L., \& Luckasson, R. (2013b). What's at Stake in the Lives of People with Intellectual Disability? Part II: Recommendations for Naming, Defining, Diagnosing, Classifying, and Planning Supports. Intellectual and Developmental Disabilities, 51, 94-101. 10.1352/19349556-51.2.094

Schalock, R. L., Thompson, J. R., \& Tassé, M. J. (Eds.) (2008). International Implementation of the Supports Intensity Scale. Washington, DC: American Association on Intellectual and Developmental Disabilities.

Schalock, R. L., \& Verdugo, M. A. (2012). A leadership guide to redefining ID/DD organizations: Eight successful change strategies. Baltimore, MD: Brookes Publishing Co.

Schalock, R. L., Verdugo, M. A., \& Gómez, L. E. (2011). Evidence-based practices in the field of intellectual and developmental disabilities: An international consensus approach. Evaluation and Program Planning, 34, 273-282.

Seo, H., Shogren, K.A., Wehmeyer, M.L., Hughes, C., Thompson, J.R., Little, T.D., \& Palmer, S.B. (in press). Examining Shared Measurement Properties and the Score Comparability 
Between Two Versions of the Supports Intensity Scale. Career development and transition for exceptional individuals.

Shogren, K. A., Thompson, J. R., Wehmeyer, M. L., Chapman, T., Tasse, M. J., \& McLaughlin, C. A. (2014). Reliability and validity of the supplemental protection and advocacy scale of the Supports Intensity Scale. Inclusion, 2(2), 100-109. doi: 10.1352/2326-6988-2.2.100

Smit, W., Sabbe, B., \& Prinzie, P. (2011). Reliability and validity of the Supports Intensity Scale (SIS) measured in adults with physical disabilities. Journal of Developmental and Physical Disabilities, 23, 277-287. doi: 10.1007/s10882-011-9227-3

Tassé, M. J., \& Craig, E. M. (1999). Critical issues in the cross-cultural assessment of adaptive behavior. In R. L. Schalock (Ed.), Adaptive behavior and its measurement: Implications for the field of mental retardation. Washington, DC: American Association on Mental Retardation.

Thompson, J. R., Bradley, V. J., Buntinx, W. H. W, Schalock, R. L., Shogren, K. A, Snell, M. E., ...Yeager, M. H. (2009). Conceptualizing supports and support needs of people with intellectual disability. Intellectual and developmental disabilities, 47(2), 135-146. doi: $10.1352 / 1934-9556-47.2 .135$

Thompson, J. R., Bryant, B., Campbell, E. M., Craig, E. M., Hughes, C., Rotholz, D. A., ...Wehmeyer, M. L. (2004). Supports Intensity Scale user's manual. Washington, DC: American Association on Mental Retardation.

Thompson, J. R., Bryant, B. B., Schalock, R. L., Shogren, K. A., Tassé, M. J., Wehmeyer, M. L.,...Rotholz, D. A. (in press). Supports Intensity Scale - Adult Version. Washington,DC: American Association on Intellectual and Developmental Disabilities.

Thompson, J. R., Hughes, C., Schalock, R. L., Silverman, W., Tassé, M. J., Bryant, B., ...Campbell, E. M. (2002). Integrating supports in assessment and planning. Mental Retardation, $40 \quad$ (5), 390-405. doi: 10.1352/0047-6765(2002)040<0390:ISIAAP $>2.0 . \mathrm{CO} ; 2$

Thompson, J. R., McGrew, K. S., \& Bruininks, R. H. (2002). Pieces of the puzzle: Measuring the personal competence and support needs of persons with mental retardation and related developmental disabilities. Peabody Journal of Education, 77(2), 21-7. 
Thompson, J. R., Tassé, M. J., \& McLaughlin, C. A. (2008). Interrater reliability of the Supports Intensity Scale (SIS). American Journal of Mental Retardation, 113, 231-237. doi: 10.1352/0895-8017(2008)113[231:IROTSI]2.0.CO;2

Thompson, J. R., \& Viriyangkura, Y. (2013). Supports and support needs. En Michael L. Wehmeyer (Ed.), The Oxford Handbook of Positive Psychology and Disability (pp. 317337). New York: Oxford University Press.

Thompson, J. R., Wehmeyer, M. L., Hughes, C., Shogren, K. A., Little, T. D., Copeland, S. R., ...Tassé, M. J. (in press). Supports Intensity Scale - Children's Version. Washington, DC: American Association on Intellectual and Developmental Disabilities

Thompson, J. R., Wehmeyer, M. L., Hughes, C., Shogren, K. A., Palmer, S. B., \& Seo, H. (2014) The Supports Intensity Scale-Children's Version: Preliminary Reliability and Validity. Inclusion, 2(2), 140-149. doi: 10.1352/2326-6988-2.2.140

van Loon, J. (2006). Los apoyos en Arduin. Sobre la diversas facetas de los apoyos y la implementación de la escala SIS en una organización de servicios. Siglo Cero, 37(4), 1734.

van Loon, J. (2009). Uso de la escala de intensidad de apoyos en la práctica: asignación de recursos y planificación de apoyos individuales basados en la escala de intensidad de apoyos. Siglo Cero, 40 (1), 54-66.

Verdugo, M. A. (1994). El cambio de paradigma en la concepción del retraso mental: la nueva definición de la AAMR. Siglo Cero, 25(5), 5-24.

Verdugo, M. A., Arias, B., Guillén, V., \& Vicente, E. (2014). La Escala de Intensidad de Apoyos para Niños y Adolescentes (SIS-C) en el contexto español. Siglo Cero, 45(1)24-40.

Verdugo, M. A., Arias, B., \& Ibáñez, A. (2007). Escala de Intensidad de Apoyos (SIS). Manual. Adaptación española. Madrid: TEA.

Verdugo, M. A., Arias, B., Ibáñez, A., \& Gómez, L. E. (2006). Validation of the Spanish version of the Supports Intensity Scale. Journal of Applied Research in Intellectual Disabilities, 19 (3), 274. 
Verdugo, M. A., Arias, B., Ibáñez, A., \& Schalock, R. L. (2010). Adaptation and psychometric properties of the Spanish version of the Supports Intensity Scale (SIS). American Journal of Intellectual and Developmental Disabilities, 115(6), 496-503. doi: 10.1352/1944-7558115.6.496

Weiss, J. A, Lunsky, Y., Tassé, M. J., \& Durbin, J. (2009). Support for the construct validity of the Supports Intensity Scale based on clinician rankings of need. Research in Developmental Disabilities 30(5), 933-41. doi: 10.1016/j.ridd.2009.01.007

Wehmeyer, M. L., Chapman, T. E., Little, T. D., Thompson, J. R., Schalock, R. L., \& Tasse, M. J. (2009). The efficacy of the Supports Intensity Scale (SIS) to predict extraordinary support needs. American Journal on Mental Retardation, 114, 3-14. doi: 10.1352/2009.114:3-14 